\title{
IMPACTS OF IMPLEMENTING GEOGEBRA ON ELEVENTH GRADE STUDENT'S LEARNING OF EUCLIDEAN GEOMETRY
}

\author{
A. Bayaga \\ Department of Mathematics, Science and Technology Education \\ University of Zululand, South Africa \\ Affiliate: Department of Information Systems, University of Cape Town, South Africa \\ e-mail: bayagaa@unizulu.ac.za
}

\section{M. Mthethwa}

Department of Mathematics, Science and Technology Education

University of Zululand, South Africa

e-mail: Mthembenimthethw3@gmail.com

\section{J. Bossé*}

Department. of Mathematical Sciences

email: bossemj@appstate.edu

\section{Williams*}

Department of Mathematics Education

email: dawilli6@ncsu.edu

*Appalachian State University

North Carolina, United States

\section{ABSTRACT}

The aim of the study was to evaluate the efficiency of applying GeoGebra software as a teaching tool to enhance high poverty, rural grade 11 students' understanding of Euclidean geometry circle theorems. The experimental group received instruction on how to use, make simple constructions, and measure elements in GeoGebra. The control group was taught in a traditional lecture method. Using a quantitative research design, the findings indicated that the use of GeoGebra had a statistically significant effect on the students' ability to correctly complete problems regarding some circle geometry theorems. Additionally, using a Likert scored questionnaire, students demonstrated that they valued the use of GeoGebra and appreciated this learning innovation. Altogether, students who interacted with GeoGebra were highly engaged in the learning processes and actively collaborated with other students rather than remaining passive learners. The students who participated in the study evaluated GeoGebra as an appropriate tool to assist them in the learning of mathematics.

Keywords: Euclidean geometry, GeoGebra, technology, pedagogy, visualization 
The news that Euclidean geometry would again be mainstreamed in the mathematics curriculum attracted many outcries into how this would affect already stagnating results in national secondary mathematics scores. Umalusi (2014), South Africa's educational quality assurance body, opined that the re-introduction of the demanding topics of Euclidean geometry and probability would likely add to students' poor performance of mathematics. This was partly because Euclidean geometry was considered to require higher order inductive, deductive, and intuitive reasoning (Goos et al. 2003; Department of Basic Education (DBE) 2010; Department of Basic Education 2012).

Despite higher order reasoning being categorized as worthwhile, rural public school students struggled to succeed with questions on national exams requiring the use of higher order reasoning. According to a report regarding student success on the Matric (South Africa's final grade 12 exam), students performed reasonably well on lower order reasoning questions $(59 \%)$, but were below par on questions requiring application (34\%) and analysis (38\%) and rural learners performed even more poorly (DBE 2015). Rural students' poor performance on higher order reasoning questions and geometry negatively impacted on the nation's overall mathematics performance (DBE 2015). It became disconcerting that mathematics students from rural, high-poverty schools performed better on lower order reasoning questions but struggled on questions that required logic, reasoning, visualization, and critical thinking, as commonly necessary in the study of Euclidean geometry.

To address this learning gap, researchers proposed the use of technology, specifically GeoGebra, in the rural classroom context. GeoGebra had been proven to enhance urban students' higher cognitive thinking skills. Numerous studies reported that technological interventions offered new opportunities for learners to employ higher order reasoning skills (e.g., analyzing, conjecturing, justifying, and proving ideas) and communicate their mathematical thinking (Goos et al. 2003; Duncombe 2011; Stols and Kriek 2011; Stols 2012). Despite significant past research regarding the use of technology in mathematics teaching and learning (e.g., Lei and Zhao 2007; Tall 2010), Chigona, Chigona and Davids (2014) argued that there existed only limited research regarding how technology had been applied in developing countries and to what result. In the case of South African rural schools and other developing nations, electronic technologies such as computers, their hardware, software, internet connectivity and laboratories to contain these technologies have not been widely affordable and utilized (Guven 2012; Lim et al. 2013; Stols and Kriek 2011).

This background argued for the need to investigate means of assisting South African students from high-poverty, rural schools in the domain of geometry. It was questioned if 
student weaknesses in geometric understanding and application could be mitigated by employing GeoGebra in manners similar to instructional methodologies more common in South Africa's urban schools. GeoGebra was selected because it was commonly used in urban schools, it was free, and, after installation, it did not require internet connectivity.

As previously noted and as noted in following discussions, research regarding the improvement of student mathematical understanding using GeoGebra and other dynamic mathematics environments is far from novel. This study had, however, an additional dimension to consider. If the use of GeoGebra proved effective in this high-poverty environment, it could demonstrate potential for this type of intervention in other developing nations.

\section{LITERATURE REVIEW}

The background literature for this study focusses on two interconnected notions. First, we consider Mathematics and technology applications in the learning of mathematics. Then, we specifically consider student learning through GeoGebra use.

Research demonstrates that dynamic mathematical environments can provide a rich learning environment promoting social interaction, critical thinking skills, and comprehensive learning experiences (Shadaan and Leong 2013; Lim et al. 2013). Unay and Ozmen (2006) suggest that, if the technology is used for higher-order reasoning, it can result in increased mathematical achievement. Bansilal (2015) reports that pre-service teachers' use of technology has changed the landscape within which mathematics teaching and learning enfolds, made their learning and teaching tasks easier, and provided opportunity for variation in mathematical teaching and learning capable of boosting student conceptual understanding. Wang (2008) argues that technology-supported collaborative learning has a positive effect on students' performance. More specifically, Guven (2012) argues that the use of dynamic geometry software in mathematics education positively affects student learning.

Research reports that the use of GeoGebra: promotes experimental learning through multirepresentational investigations; aids learners and teachers in processing mathematical concepts through problem-solving; and encourages users to engage with the content, reason appropriately, visualize, and make connections to improve learning (Bansilal 2015; Chigona et al. 2014). Numerous studies articulate various advantages of GeoGebra usage in mathematics teaching and learning (Akkaya, Tatar and Kagizimanli 2011; Dogan and Icel 2011; Guven 2012; Hohenwarter, Jarvis and Lavicza 2009). Dogan and Icel (2011) define the user-friendly nature of GeoGebra through its easy-to-use interface, multilingual menus, commands, and help. This interface encourages learners to experience mathematics through multiple presentations, experiment with mathematical notions, employ guided discovery, and personalize their own 
creations and communications.

Proponents of GeoGebra report that learners can manipulate variables easily by using dynamic sliders, parameters, or by simply dragging free objects around the plane (Hohenwarter et al. 2009; Shadaan and Leong 2013). This can help students grasp the notions of independence, dependence, variants, and invariants (Akkaya et al. 2011; Hohenwarter et al. 2009). Using GeoGebra, students have the opportunity to solve problems by dynamically investigating mathematical relations.

Cooperative learning has long been touted as a powerful pedagogy for mathematics learning (Dubinsky and Schwingendorf 1990).

While the potential for GeoGebra to empower mathematics teaching and learning seems indisputable, it must be acknowledged that the vast majority of studies purporting positive results were held in urban school in developed nations. Little is known as to whether GeoGebra is applicable to high-poverty, rural students to improve their understanding of Euclidean geometry, particularly when the use of GeoGebra is limited.

\section{THEORETICAL FRAMEWORKS}

Two frameworks inform this study. They include Rogers' (2003) Diffusion of Innovation Model and constructivist learning theory. These are addressed below.

\section{Diffusion of Innovations Model}

Various attributes influence the adoption of an innovation such as GeoGebra. Rogers (2003) describes five phases that a person goes through when adopting a new technology: knowledge (the learner receives information about the innovation); persuasion (the learner forms an attitude, positive or negative, toward the innovation); decision (the learner decides whether he wants to use the innovation); implementation (the learner puts the innovation into practice); and confirmation (the learner strengthens his or her decision to adopt the product, reduce the use of the product, or discontinue use of the product) (West, Waddoups and Graham 2006).

In this research project, GeoGebra was recognized as a novel innovation by all participants in this study. Thus, the participants needed the opportunity to experience and pass through these stages of diffusion of innovation. Therefore, in addition to determining the degree of content learning that participants experienced, it was also necessary to determine to what level they accepted this innovation.

Considering Rogers' (2003) Diffusion of Innovations model regarding the implementing of GeoGebra, it was necessary for the participating students to experience the software during implementation of the lessons. During the decision-making stage, the students had to begin 
experimenting with GeoGebra. This experimentation lead to self-learning. After early experimentation, students faced some problems and technical challenges including usage over time and the effectiveness of the innovation. It was conjectured by the researchers that the magnitude and nature of technical challenges students faced may determine whether they would want to use the innovation again or dismiss it altogether. This would be revealed when the students were given the opportunity to evaluate the innovation. It would only be after overcoming technical challenges that the students would possibly want to integrate the innovation in everyday learning activities. The decision would be based on how well the implementation process proceeded and how the students valued the adoption of the new technology. The continuation decision reported by students would indicate that the technology was useful and therefore worth applying in the teaching of mathematics. However, if students found GeoGebra use to be complicated, they may call for discontinuation. This may mean that the software was not useful for teaching mathematics in rural environments.

\section{Constructive theory and GeoGebra software}

When innovation is adopted, it becomes a tool through which the learner constructs knowledge. Constructivist scientist regard learning as the construction of knowledge. It is argued that constructivist instructional practices empower students to: seek new knowledge and understanding for themselves, in the context of their own unique, individual experiences (Donaldson 2014; Piaget 1950); deepen their knowledge at their discretion; and ask questions, clarify concepts, and share experiences. According to Donaldson (2014), constructionism is based on the fact that learning is an active process, in which people actively construct knowledge from their experience in the world. Thus, learners do not just receive ideas, they form them and they construct new knowledge with particular effectiveness when they are engaged in constructing personally meaningful products (Piaget 1950). When constructivist instructional techniques are implemented, teachers are enthusiastically transformed into facilitators, guiding the students to inquire, explore, discover, and generate new ideas.

Students construct their own understanding and knowledge of the world, through experiencing things, reflecting on those experiences, and reconciling previous and new notions (Bereiter 1994). Learners explore and assess their understanding before, during, and after interacting with learning activities (Piaget 1950).

White (2012) indicates that GeoGebra is a free, user-friendly software that perfectly combines geometry and algebra in a manner so that the user can individualize the ways in which they interact with the content. As the software platform facilitates user investigation, users can construct meaning and knowledge in novel and ways unique to the user. Thus, through student 
interaction and collaboration in GeoGebra investigations, students construct knowledge regarding geometric ideas and participate in higher order levels of thinking as well as critical and creative thinking experiences. Exploring geometric ideas through GeoGebra scaffolds student learning, allowing students to form their own interpretations while exploring and visualizing geometric concepts.

\section{Connecting diffusion of innovation with collaborative learning}

The two preceding frameworks play prominently in this study in an interconnected manner. Since GeoGebra was an innovation for all the participants in this study, the participants' perception regarding its effect in learning was considered important. Beyond whether or not the use of GeoGebra led to greater student learning, this study believed it is important to know whether students valued GeoGebra as a learning tool. If they did not: potentially positive result of learning may be more attributable to other factors in the study; future potential use of GeoGebra with this group of students could result in self-fulfilling failure; and it might potentially bode poorly for other implementations of GeoGebra among other groups of students, even regarding other mathematical topics. Moreover, if study participants did not value GeoGebra as a leaning tool, it might speak to sociocultural dynamics at play that would minimize the use of GeoGebra in high poverty, rural schools.

The GeoGebra classroom activities were designed for students to complete while working in pairs or trios. In this study, this collaboration was contextualized in the use of an innovation, GeoGebra. Thus, dynamics associated with collaborative learning were inherently at play in the potential adoption of an innovation. Quite possibly, if the students worked singularly rather than collaboratively, the students' reaction to the innovation may have been different and the students' success on the tasks may have been different.

Notably, while the collaboration on the research tasks was contextualized in the application of a technological innovation, possibly adopting an innovation was simultaneously contextualized in collaborative learning. Altogether, both innovation and collaboration were contextualized in the other, and this argues for the importance of simultaneously considering the two frameworks.

\section{STUDY OBJECTIVE}

The primary goal of this study was to assess the efficiency of using GeoGebra as a teaching tool in a high poverty, rural context in which technology was previously unavailable. We sought to understand two primary ideas: whether student understanding of geometric notions improved through the application of GeoGebra over traditional instructional methods and whether the 
participating students perceived the use of GeoGebra as valuable. With the focus centering on these ideas, we sought to address research questions regarding the actual effects (pre- and posttest results on circle geometry content problems) and perceived effects (student questionnaire) regarding the benefits of using GeoGebra activities in the learning of circle geometry content. Results of this study would help inform the field of mathematics education regarding implementing GeoGebra as a technological learning tool in rural, high-poverty educational settings which do not usually experience technological support.

\section{METHODOLOGY}

\section{Research sample and design}

The participants for the current study were all Grade 11 students selected from a high poverty, rural school in the Umkhanyakude district, KwaZulu-Natal Province, South Africa. To define the "high poverty rate" in the province, the KwaZulu-Natal Department of Education Annual Report for 2013, reports,

"Fifty percent (50\%) of the people of KwaZulu-Natal are considered to be living in poverty. The following gives an indication of living conditions:

- $\quad 9 \%$ of households live in informal dwellings and $22 \%$ live in traditional dwellings;

- $\quad 61.2 \%$ of rural households are without electricity and $57 \%$ use wood for cooking food; and

- Only $35.2 \%$ of households have a tap within their dwelling and $52.3 \%$ have no flushing or chemical toilet.

The majority of learners in the province live in impoverished areas where education is not easily accessible.” (KwaZulu-Natal Department of Education 2013, 20-21).

This school was selected because it was recognized as a high poverty, rural school with a dearth of technology available to teachers and students. Three mathematics classes consisting of a total of 112 learners were selected. Both the experimental group and the control group consisted of 56 students. The pre-test and post-test were administered to both groups in the form of an achievement test (See the Appendix.) While the experimental group received a treatment where they were instructed using GeoGebra, the control group was taught in the traditional, lecture approach lacking any technological teaching or learning aids. Both the control and treatment techniques lasted for one week.

Due to the high poverty nature of the school, this study was unable to provide a computer for each student participant. Thus, two or three students participating in the experimental group were grouped together to work on each computer. More than allowing students to collaborate on the GeoGebra based activities, in all respects, this grouping of students on computers 
facilitated student collaboration.

Notably, the instruction provided to the control group was minimal. The experience of the experimental group began with a 90-minute session introducing the students to GeoGebra and techniques of constructions and measurement. In this class period, students were teamed up on computers, shown how to construct circles, line segments, rays, tangents, and secants, and instructed on how to measure distances and angles. They were then allowed simply to free play for the rest of a class period. Beginning on the second class period, students were instructed to form a circle and simply investigate any ideas they could imagine regarding chords, central angles and inscribed angles and relationships they could find. On the

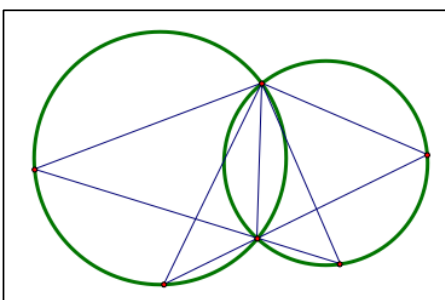

Figure 1. third class, they were asked to consider the interplay of radii and chords. On the fourth day, they were to inscribe a quadrilateral and investigate relationships they could determine among the angles of the inscribed quadrilaterals. On the fifth day, they were asked to construct two circles that intersect at two points (See Figure 1) and segments to construct inscribed angles, and investigate angles for relationships. On all of these investigations, no other instructions were given to the teams of students.

The control group, however, received direct, lecture-based, instruction on a static chalkboard regarding: the measure of central and inscribed angles; a radius perpendicular to or bisecting a chord; inscribed angles on intersecting circles; and properties of cyclic quadrilaterals. These lectures included no hands on activities and students took all notes from teacher illustrations on the board and teacher communication.

Two instruments were used in order to evaluate results: (1) achievement test assessed learners' growth in Euclidean geometry circle theorems and (2) a questionnaire to obtain the learners' views on the use of GeoGebra. The questionnaire allowed the learners to evaluate the software usage and opine on its effects in their growth in understanding of cyclic geometry theorems and proofs. At the end of the contact classes, a post-test was administered to both groups. Notably, since the control group did not receive instruction using GeoGebra, the questionnaire was not given to them.

Circle theorems were selected as the topic for this investigation for a number of reasons. First, circle theorems tend to be the culminating topic in traditional courses in Euclidean geometry. Second, the understanding and proofs of circle theorems most often necessitate understanding of much geometry which precedes it (e.g., proportions, similar triangles, and parallel lines). Third, students perennially seem to have more difficulty with circle theorems than other concepts. The researchers believe that this may be so because, coming near the end 
of the geometry course, these theorems are considered both last and in a rush to complete compulsory topics. Thus, they are glanced over and not covered in the same detail as are previous topics. Therefore, altogether, circle theorems seem most promising to see whether the use of GeoGebra could produce noticeable improvement in student understanding.

The researchers ensured that each respondent (student) was motivated to do well, each student understood clearly what the achievement test required, there was a conducive environment to encourage best efforts, and each respondent had an equal chance to demonstrate his/her achievement. In developing the achievement test, while the researchers targeted the processes of problem solving, critical interpretation, and evaluative judgment, the primary focus was on finding the evidence of specific growth in geometric understanding of circle theorems and proofs. Based on literature in the field, the achievement test consisting of ten questions regarding circle geometry was prepared by the researchers. The focus of the questions of the achievement were strictly on expected grade 11 geometric understanding; each question consisting of four options included one correct answer and three obfuscatory answers. Content validity of the test questions was determined via the opinions of the two university geometry experts and five experienced senior secondary mathematics teachers. They all assisted in the design of an achievement test on circle geometry and the questionnaire to be supported by current reform ideas in mathematics education.

\section{Instrumentation and data quality}

Prior to the research project, the researchers and secondary classroom teachers twice field tested all aspects of the research project with similar populations of grade 11 students in the same school in which the research would be conducted with similar activities that would be used in the study. This allowed the research team to refine tasks and understand the resources and amount of time needed for students to complete the research tasks (Chetty and Grinter 2007; Skarma-Grover et al. 2009). It also ensured content validity and reliability with the research tasks and reiterated to the researchers the need to ensure that student groups were sufficiently heterogeneous according to geometric levels of understanding in order to maximize student interaction. Most importantly, the field tests informed the research team as to what data from the study would be most realistically accessible and usable in the study.

Prior to the pre-study, the authors also consulted experienced colleagues for proof reading and verification to assist in developing and assessing the circle geometry research tasks. Criteria that were investigated in and among the research tasks regarding the ordering of tasks, their respective importance, curbing ambiguity in the language and presentation of the task, and making sure that items are concise, clear, and to the point. Additionally, through both the 
assistance of the geometry experts and results for the field tests, item analysis of the test was carried out by calculating the levels of difficulty per task. The KR-20 reliability coefficient (Baykul 2000; Isman and Eskicumali 2003) was calculated for each test item. The items were evaluated according to difficulty levels provided in Table 1 . Through this, only tasks which scored in the range $0.30 \leq \mathrm{KR}-20 \leq 0.5$ were retained others within this range substituted. In the end, average level of difficulty of items was determined to be at an intermediate level (0.37), which was considered to be reliable for the grade 11 students.

Table 1: Difficulty levels of items (Baykul 2000; Isman and Eskicumali 2003)

\begin{tabular}{|l|l|}
\hline Difficulty of item & Assessment of item \\
\hline $0.70-1.00$ & too easy \\
\hline $0.50-0.69$ & easy \\
\hline $0.30-0.49$ & intermediate difficulty \\
\hline $0.50-0.69$ & easy \\
\hline
\end{tabular}

Extemporaneous communication between the research team and the students in the field tests, along with literature regarding geometric learning, the use of GeoGebra, and diffusion of innovation led to the development of a questionnaire through which to investigate study participants' willingness to adopt GeoGebra as a learning tool. The research questionnaire was composed of a Likert scale (ranging from strongly disagree to strongly agree) of prompts that allowed the respondents to assess the use of GeoGebra in Euclidean geometry. The questionnaire was comprised of fourteen items grouped under eight themes.

\section{Data analysis}

Respondents were given deadlines to finish all research tasks: 60 minutes on achievement test and 10 minutes for completing the questionnaire. After the achievement test (pre-and post-test) had been administered to the experimental $(\mathrm{N}=56)$ and control group $(\mathrm{N}=56)$, learner responses were coded as 1 for a correct response and 0 for a false or void response. The scores of the learners were tallied and sorted from highest to lowest.

The scores of the pre-test was analyzed using an independent sample $t$-test. The pre-test mean score of the control and experimental groups were compared to ascertain their level of performance to eliminate bias. To determine whether any statistically significant differences existed between the post-test mean score of the control and experimental group, an independent sample $t$-test was again carried out. This was to assess the extent of GeoGebra impact on student learning as compared with the traditionally taught control group.

Furthermore, descriptive analysis was used to analyze the data from the survey of the 
questionnaire. Items measured on a Likert scale including: $1=$ Strongly Disagree, $2=$ Disagree, $3=$ Agree, and $4=$ Strongly Agree were analyzed. Percentages were calculated for each scale or item for better analysis. The percentage responses of the 14 items shed more light on the GeoGebra application in the learning of circle geometry.

\section{Confounding variables}

Notable confounding variables can be recognized in this study and its methodology. While some of these are addressed in the discussion section later in this article, one issue warrants immediate consideration. In this study, for the experimental group, GeoGebra activities were used through which to facilitate communicative, collaborative, constructivist learning experiences. The control group experienced neither GeoGebra nor learning experiences beyond the traditional lecture. Therefore, the experimental group received two types of differentiated experiences (an alternate pedagogy and the use of GeoGebra). Unfortunately, these two dimensions cannot be disaggregated to determine the effect of the constructivist pedagogy versus the use of GeoGebra.

\section{Research ethics}

To ensure that all ethical considerations were considered for this study and its participants, a proposal for this study was approved by review boards from two of the universities at which the researchers work and the rural school in which the research was undertaken. Thus ethical considerations of the study and the safety of the participants were ensured.

\section{FINDINGS}

To determine whether any statistically significant differences existed between the pre-test mean score of the control and experimental groups, an independent sample $t$-test was performed as illustrated in Table 2.

Table 2: Results of the independent t-test on the pre-test of both groups

\begin{tabular}{|l|c|c|c|c|}
\hline \multicolumn{1}{|c|}{ Group } & Mean & SD & T & Sig (2 tailed) \\
\hline Experimental (56) & 6.36 & 2.64 & 1.62 & 0.108 \\
\hline Control (56) & 5.5 & 2.9 & & \\
\hline
\end{tabular}

T-value significant at $p<0.05$

Table 2 shows that the control group obtained a mean score of 5.5 while experimental group obtained a mean score of 6.36. The mean score difference between the groups was 0.86 with $t$ value of 1.619419. Nonetheless, the $p$-value was $0.108221(p<0.05)$ indicating that the 
difference in the mean score was not statistically significant. This result illustrated that both the learners in the control and experimental group were similar in abilities before the treatment was administered.

The GeoGebra lessons for the experimental group and the traditional method of teaching circle geometry were undertaken. After the lessons, the post-test scores were analyzed as indicated in Table 3. Notably, neither the experimental nor the control groups had access to GeoGebra on the post-test.

Table 3: Results of independent t-test on the post-test of both groups

\begin{tabular}{|l|c|c|c|c|}
\hline \multicolumn{1}{|c|}{ Group } & Mean & SD & T & Sig (2 tailed) \\
\hline Experimental (56) & 9.45 & 1.92 & 4.38 & 0.000 \\
\hline Control (56) & 7.52 & 2.64 & & \\
\hline
\end{tabular}

T-value significant at $p<0.05$

To determine whether any statistically significant differences exist between the post-test mean score of the control and experimental group, an independent sample $t$-test was carried out. Table 3 shows that the control group obtained a mean score 7.52, while the experimental group obtained a value of 9.45. The mean score difference between the groups was 1.93 with a $t$-value of 4.384833. However, the $p$-value was low at $0.000027(p<0.05)$, indicating that the difference in the mean score of the groups was statistically significant.

Table 4: Results of the paired samples t-test

\begin{tabular}{|c|l|c|c|c|c|}
\hline Pair & \multicolumn{1}{|c|}{ Group } & Mean & SD & T & Sig (2 tailed) \\
\hline 1 & $\begin{array}{l}\text { Post-test, pre-test scores } \\
\text { (Experimental) }\end{array}$ & 3.09 & 2.72 & 13.7 & 0.000 \\
\hline 2 & $\begin{array}{l}\text { Post-test, pre-test scores } \\
\text { (Control) }\end{array}$ & 2.02 & 1.42 & 14.58 & 0.000 \\
\hline
\end{tabular}

T-value significant at $p<0.05$

The findings presented in Tables 2 to 3 show that the learners in the experimental group performed better on the post-test after using GeoGebra than those in the control group using the traditional learning method. The learners in the experimental group performed better in the post-test compared to the control group. A paired samples $t$-test was conducted to compare the pre-test and post-test scores for the experimental and control groups. The result as illustrated in Table 4 shows that the mean score difference between the post-test and pre-test of the experimental group was 3.09 as compared to the control group with 2.02. For the experimental group, the $t$-value obtained was 13.7 and the $p$-value obtained was 0.000 which was low $(p<$ 
.05) indicating the difference between the pre-and post-test score was statistically significant. For the control group, the $t$-value obtained was 14.58 and the $p$-value obtained which was 0.000 that was low $(p<.05)$ indicating the difference between the pre-test and post-test score was statistically significant.

To take learners opinions on learning Euclidean geometry with GeoGebra, 14 questions/items were asked via the questionnaire.

The percentage responses shown in Table 5 (cf appendix) from the 14 items are grouped into the eight elaborated as follows.

- Excitement/Enjoyment/Confidence. Approximately 95 per cent of participants felt excited learning Euclidean geometry using GeoGebra. Of the students, 82 per cent enjoyed the lesson and 86 per cent felt confident. Only 5 per cent of the respondent did not feel excited as well as 18 per cent were not confident in the GeoGebra treatments.

- Engagement. There were only two learners who felt disengaged and 54 learners who agreed or strongly that there were highly engaged in the lessons. This was 96 per cent of the learners who believed that GeoGebra engaged them in the lessons. While this may speak of the application of GeoGebra in learning, it may also confirm the effects of cooperative learning, where students shared learning experiences and principles of constructivism (exploration, discovery, and reinventing new mathematical knowledge) were made explicit.

- Connections. The results show that majority of the students $(80 \%)$ believed that, through the research tasks, they could make connections with previous mathematical information. This seemingly helped students to take each lesson seriously, recognizing its connections to past concepts and potential impact on upcoming activities. Interestingly, and seeming contradictorily, 44 per cent of students believed that only brilliant students can do well in Euclidean geometry without GeoGebra while 56 per cent of the experimental group disagreed. This may reveal the degree to which students the difficulty to learn Euclidean geometry via traditional teaching approaches.

- Visualization. Learners agreed and strongly agreed that their visualization has improved after they had complete lessons using GeoGebra (90\%). There results confirm that, using GeoGebra, students' mental schemata were utilized to the fullest. This is crucial for higher cognitive level questions focusing on analysis, synthesis, and information application.

- Interaction/Creative and Critical. The result indicate that 91 per cent of students liked their interactions with GeoGebra and teacher-student interactions. Of the participants, 93 per cent felt that using GeoGebra in the investigation of circle geometry enabled them to be creative 
and critical - higher reasoning skills required in solving challenging mathematics questions.

- Logical assumptions. About 84 per cent of students believed that the application of GeoGebra in learning Euclidean geometry had improved their understanding of how to work on systematic problems (logic). This is very important in proving theorems and breaking down information which might be embedded in circle geometry - most probably from previous information, like knowledge of properties of parallel lines etc.

- Outcome/Improvement/Prediction. A large majority of students agreed (91\%) that their learning of Euclidean geometry would improve through using GeoGebra and 78 per cent of students believed that they were going to do well in mathematics tests and examinations.

- Reasoning Skills. Collectively, 78 per cent of students agreed and strongly agreed that learning Euclidean geometry using GeoGebra improved their reasoning skills.

In summary, the eight themes all provide indication that learners perceived that they benefited through the use of GeoGebra in the learning of circle geometry and hence evaluated it in a positive light. In the following section, the responses from the eight themes of the fourteen questionnaire items are linked to student performance on the achievement.

\section{DISCUSSION}

The previous research questions are now reconsidered. The first question; how does the use of GeoGebra assist students in learning circle geometry content? Consistent with the findings of Shadaan and Leong (2013), this study revealed that the use of GeoGebra can have tremendous impact on learners gaining knowledge in circle geometry. The overwhelming majority of the students in the experimental group indicated that applying GeoGebra in the learning of circle geometry theorem and proofs had yielded positive result in terms of logical thinking, confidence, interaction, engagement, connection, reasoning, creativity, as well as understanding. These learners also reported that they were confident that they would improve in tests and examinations because of using GeoGebra.

Some students noted that technological facilities in GeoGebra afforded them greater opportunities to learn. For instance, colored geometric elements (e.g., lines and angles) in GeoGebra improved their ability to follow and produce proofs. The findings further confirm what studies have reported about GeoGebra's ability to induce critical thinking skills and comprehensive mathematical understanding (Shadaan and Leong 2013; Unay and Ozmen 2006).

After completing learning activities in GeoGebra, student communication revealed that they better supported their ideas with geometric reasoning and sound judgment. This 
demonstrated a deepening understanding of axioms and theorems. These skills, as argued by Goos et al. (2003), form high-order reasoning abilities required to apply and analyze difficult mathematical challenges. Although, the students' responses at times showed that some students continued to struggle somewhat with reasoned conjecturing, this could be due to the structured time allocated to them to complete the research tasks, and the increasing cognitive demands of mathematical tasks through the entirety of the tasks, and the limitation of time for them to comprehend ideas before attempting to implement them.

An implication from this study is that learning Euclidean geometry using GeoGebra both improved students' geometric reasoning skills and enhanced important skills to excel in the lifelong learning of mathematics. Thus, GeoGebra software adoption and implementation serves to scaffold the teaching and learning of more difficult and somewhat abstract aspects of Euclidean geometry. The statistically significant improvement in experimental students' conceptual understanding of circle geometry as compared to the control group attest to this finding.

The second question in the study was: what technological attributes of GeoGebra can be deem useful for learners in learning circle geometry? Results from this study are in agreement with Rogers' (2003) diffusion of innovation model and the case made by West et al. (2006). These findings revealed that learners adopted the technology well, received necessary information, formed positive attitudes towards the innovative teaching tool, decided to apply the innovation, implemented it, and confirmed its usefulness. The students were able to acquire knowledge because it was given in a meaningful context. Hence, the GeoGebra-based instruction enhanced communication and collaboration in the learning environment. Additionally, our findings comport with those of Bansilal (2015) and Stylianou (2010), that the effective use of technology helps students to see connections between representations by providing opportunities for them to link different representations of a mathematics objects.

The results of this study also agree with that of Dogan and Icel (2011) whose work revealed that GeoGebra had positively affected students' learning and achievement and improved their motivation. While students regarded the use of GeoGebra as helpful, researchers noted a marked increase in observable cooperative and collaborative learning among the students. Lim et al. (2013) and Wang (2008) argue that technology-rich environment lead to classroom success stories. In this study, students worked towards an environment in which all were expected to be successful.

The link of the findings to the five processes of Rogers (2003) diffusion of innovation model reveals that students view GeoGebra usage as a worthwhile and innovative tool to understand Euclidean geometry and proof. This was attributed to the constructivist approach of 
learning provided by the GeoGebra environment. Students engaged actively in the learning process, constructed their own understanding, and gained knowledge (Donaldson 2014; Hohenwarter et al. 2009). According to White (2012) and Donaldson (2014), the constructive learning theory is essential since it encourages interaction, learner-centeredness and yielding towards the zone of proximal development. The researchers, in agreement with Shadaan and Leong (2013), believe that technology usage is a motivational tool that can uplift students' confidence and enhance their learning process and that technology provides an essential tool to change students' valuing of mere memorization of facts to accurate understanding of mathematical and relational variants and invariants (Akkaya et al. 2011; Guven 2012). Based on this current study, GeoGebra equips learners with effective inquiry skills needed to find and process new information using digital technologies.

At this point, since findings from this study parallel the results of previous studies, it may be questioned how this study extends the literature. The answer may be in the minimalist instruction and guidance the students received in the use of GeoGebra in this study. Student groups independently sought out, discovered, and investigated possible relationships among elements under the conditions of circle geometry. Thus, little costs was necessary for the school to see positive results in student learning. No costly curricula was needed for students to learn. Similarly, the teachers involved in this activity required no instruction in the use of GeoGebra than did the students to see positive results in student learning. Therefore, this study advances the literature in the limited amount of interaction the participating students had with GeoGebra, yet with positive results in learning. In parallel, this limited opportunity with GeoGebra was sufficient for students to value the innovation for learning.

\section{GeoGebra in high poverty, rural settings}

While the preceding questions have been addressed through this study, it is important to return to the central question to this study: whether GeoGebra positively affected learning and attitudes toward an educational innovation of this sort in a high poverty, rural school. The fact that this is so, speaks volumes to teaching, learning, and infrastructure issues related to rural education.

First, the model employed demonstrates that, while technology assists learning in many ways, an overabundance of technology is unneeded. When students share technology at a ratio of two or three students to one computer or tablet, this can have the benefit of learning with technology and simultaneously developing a collaborative learning environment. In high poverty, rural educational settings where technology can neither be offered at the rate of one computer to one student nor outside of a computer lab used by as many classes of students as 
possible and certainly not by one student throughout the entire day. Although untested in this study, the researchers conjecture that this forced collaboration may be more valuable than each student having his own computer or technology. Nevertheless, the realization that not all students need a computer or tablet of their own connotes that resourcing high poverty, rural schools may not be as difficult or costly as it may seem.

Second, rural students can learn at a pace seemingly commensurate with non-rural students if provided supportive instructional environments and appropriate resources. This finding is important as it can ameliorate the opinions of those who seem to have lower expectations of learners based on lower socio-economic status and lesser access to resources.

Third, since mathematics teachers are in high demand in non-rural communities, these non-rural schools can pay higher wages and procure the cream of the crop of teachers. High poverty, rural schools are often relegated to hiring teachers who are less desirable to the nonrural communities. Thus, it is possible that some rural teachers are among those who need greater training and support. Due to the overcrowding in high poverty schools and high student to teacher ratios, rural school teachers are often more apt to believe that lecturing is the most efficient instructional strategy. They may be unfamiliar with, or not believe in the efficacy of, inquiry based instruction, collaborative learning techniques, constructivism, or many other instructional methodologies supported by research and employed in non-rural schools. As stated in the research methodology, having made student work in groups on computer based activities may have forced students into collaborative, constructivist experiences. The success of this study may demonstrate that rural teachers need more access to and experience with constructivist instructional methodologies and that rural student learn well from these methodologies.

Since high poverty, rural schools suffer from lack of resources and funding, inexpensive, effective solutions are necessary. Fortunately, providing effective professional development to teachers in constructivist teaching methodologies can be done relatively inexpensively. Developing communities of practice and teacher coaches among school teachers can even more reduce the costs of professional development.

Unfortunately, this study may be fraught with confounding variables. Most significantly, it is not entirely clear if the use of GeoGebra affected the increases in student geometric understanding or the way GeoGebra was utilized. Placing students in groups of two or three to a computer forced them to work collaboratively. It is unclear whether the constructivist, collaborative instructional methodology or the use of GeoGebra led more to the students' increased learning. Nevertheless, the use of GeoGebra as in this study demonstrated strong results in student geometric learning. 


\section{IMPLICATIONS}

A number of significant implications arise from this study in respect to universities preparing preservice teachers. These universities directly interact with, and prepare teachers to work in, schools in the community. The teacher preparation provided at these universities directly affects students in the schools. Therefore, it is important for teacher preparation programs to well understand the particular needs in the schools in which they serve. This cannot be accomplished without time dedicated by preservice teacher faculty frequenting these schools.

Some of the findings in this study may imply that schools, teaching, and learning, even in high poverty regions, can be affected by university interaction. Thus, universities must be continually optimistic when working with schools who may be disadvantaged - even to the point of discouragement; universities must be the cheerleaders for change. Short of this may be missing the mark of the vision and mission of universities.

Preservice teachers must be on the cutting edge of pedagogical and epistemological uses of technology. They must be properly trained in the universities to employ technology to the uttermost, within the socioeconomic constraints of the schools in which they will go to serve. Preparing them for this task is the role of the university.

Results from this study may also imply that even seemingly minor changes in educational experiences my result in significant changes in learning. These changes can occur in both schools and universities. Universities must look at novel instructional modes through which to prepare their preservice teachers for current and future educational needs. However, these changes need not always require massive change. They can be subtle and simple. And potential change warrants investigation into potential effects.

\section{CONCLUSION AND RECOMMENDATIONS}

There is substantial evidence that employing GeoGebra in the teaching and learning of Euclidean geometry circle theorems in a constructivist fashion in high poverty, rural classroom yields significant learning, engages the student, and leads to increases higher order thinking. The use of GeoGebra enables students to perform better than if they are taught solely through traditional lecturing approaches. Indeed, using GeoGebra in collaborative learning environments can lead to gains in students' employing higher order reasoning, problem solving skills, and deepening understanding in Euclidean geometry.

The study confirms that as much as higher order thinking are required for attainment of Euclidean academic achievement, the even limited use of GeoGebra in rural schools in developing countries cannot be underestimated. GeoGebra is highly recommended as a freely 
available, open-source software package which can provide an invaluable assistance in mathematics teaching and learning. The study suggests future work on the investigation of the application of GeoGebra in basic geometry in relation to students with learning difficulties. Further research can be conducted to examine how GeoGebra can support primary school students' practices in mathematics.

\section{REFERENCES}

Akkaya, A., E. Tatar and T. Kagizimanli. 2011. Using dynamic software in the teaching of the symmetry in analytical geometry: The case of GeoGebra. Procedia Social and Behavioural Sciences 15: 2540-2544.

Bansilal, S. 2015. Exploring student teachers' perceptions of the influence of technology in learning and teaching mathematics. South African Journal of Education 35(4): 1-8. Doi: 10.15700/saje.v35n4a1217.

Baykul, Y. 2000. Egitimde ve Psikolojide Olcme: Klasik ve Test Teorisi ve Uygulamasi. Ankara: OSYM Yayinlari.

Bereiter, C. 1994. Constructivism, socioculturalism, and Popper's World 3. Educational Research 23(7): 21-23.

Chetty, K. and R. Grinter. 2007. HCI4D: HCI challenges in the global south. Paper presented at the 2007 Conference on Human Factors in Computing Systems. Proceedings of the Extended Abstracts Proceedings of the 2007 Conference on Human Factors in Computing Systems, San Jose, California. doi: 10.1145/1240866.1241002.

Chigona, A., W. Chigona and Z. Davids. 2014. Educators' motivation on integration of ICTs into pedagogy: Case of disadvantaged areas. South African Journal of Education 34(3): Art.\#859, 8 pages. Doi:10.15700/201409161051.

DBE see Department of Basic Education.

Department of Basic Education. 2010. Curriculum news. Improving the quality of learning and teaching. Strengthening curriculum implementation from 2010 and beyond. Pretoria, RSA: Government Printers http://www.education.gov.za/LinkClick.aspx?fileticket=RIQ3WgihTQA \%3D\&t

Department of Basic Education. 2012. National curriculum statements (NCS). Curriculum and policy statement. Intermediate phase. Grades 4-6. Mathematics. Pretoria, RSA: Government Printers.

Department of Basic Education. 2015. National senior certificate examination 2014: Diagnostic Report. Pretoria, RSA: Government Printers.

Dogan, M. and R. Icel. 2011. The role of dynamic geometry software in the process of learning GeoGebra example about triangles. International Journal of Human Sciences 8(1): 1441-1458. doi: http://dx,doi.org10.1016:/s0364-0213.(99)80061-5.

Donaldson, G. 2014. Teacher education and curriculum change in Scotland. European Journal of Education 49(2): 178-191. Doi: 10.1111/ejed.12077.

Dubinsky, E. and K. Schwingendorf. 1990. Constructing calculus concepts: Cooperation in a computer laboratory. In The laboratory approach to teaching Calculus, number 20 in MAA Notes, ed. C. Leinbach, 47-70. Mathematical Association of America, Washington, DC.

Duncombe, R. 2011. Researching impact of mobile phones for development: Concepts, methods and lessons for practice. Information Technology for Development 17(4): 268-288. doi: $10.1080 / 02681102.561279$.

Goos, M., P. Galbraith, P. Renshaw and V. Geiger. 2003. Perspectives on technology mediated learning in secondary school mathematics classrooms. Journal of Mathematical Behaviour 22(1): 73-89. 
Guven, B. 2012. Using dynamic geometry software to improve eight grade students' understanding of transformation geometry. Australasian Journal of Educational Technology 28(2): 364-382.

Hohenwarter, M., D. Jarvis and Z. Lavicza. 2009. Linking geometry, algebra and mathematics teaching: GeoGebra software and the establishment of the international GeoGebra institute. International Journal for Technology in Mathematics Education 16(2): 83-87.

Isman, A. and A. Eskicumali. 2003. Egitimde Planlama ve Degerlendirme. Istanbul: Degisim Yayinlari.

KwaZulu-Natal Department of Education. 2013. The Annual Report 2012/13. KwaZulu-Natal, Durban, Government Printers.

Lei, J. and Y. Zhao. 2007. Technology uses and student achievement: A longitudinal study. Computers \& Education 49(2): 284-296. Doi:10.1016/j.compedu.2005.06.013.

Lim, C. P., Y. Zhao, J. Tondeur, S. C. Chai and C. C. Tsai. 2013. Bridging the gap: Technology trends and use of technology in schools. Journal of Educational Technology \& Society 16(2): 59-68.

Piaget, J. 1950. The psychology of intelligence. New York, USA: Routledge.

Rogers, E. M. 2003. Diffusion of innovations. $5^{\text {th }}$ Edition. Free Press.

Shadaan, P. and K. E. Leong. 2013. The effectiveness of using GeoGebra on students' understanding in learning circles. The Malaysian Online Journal of Educational Technology 1(4): 1-11.

Skarma-Grover, A., M. Plaunche, E. Bernard and C. Kuun. 2009. HIV health information assess using spoken dialogue systems: Touchtone vs. speech. Paper presented at the $3^{\text {rd }}$ International Conference on Information and Communication Technologies and Development, Education City, Doha, Qatar.

Stols, G. 2012. Does the use of technology makes a difference in the geometric growth of pre-service mathematics teachers. Australasian Journal of Educational Technology 28(7): 1233-1247.

Stols, G. and J. Kriek. 2011. Why don't all math teachers use dynamic geometry software in their classrooms? Australasian Journal of Educational Technology 27(1): 137-151.

Stylianou, D. A. 2010. Teacher's conceptions of representation in middle school mathematics. Journal of Mathematics Teacher Education 13(4): 325-343.

Tall, D. 2010. A sensible approach to the calculus. Presented as a plenary at The National and International Meeting on Teaching of Calculus, 23-25 September 2010, Puebla, Mexico. Doi+10.1.1.377.5699\&rep=repl1\&type $=$ pdf

Umalusi. 2014. What's in the CAPS package? Mathematics. A comparative study of national curriculum statement (NCS) and curriculum and assessment policy statement (CAPS). Further Education and Training (FET) phase. Pretoria, RSA: Government Printers.

Unay, A. I. and C. Ozmen. 2006. Building structure design as an integral part of architecture: A teaching model for students of architecture. International Journal of Technology and Design Education 16(3): 253-271.

Wang, Q. 2008. A generic model for guiding the integration of ICT into teaching and learning. Innovations in Education and Teaching International 45(4): 411-419.

West, R., G. Waddoups and C. Graham. 2006. Understanding the experience of instructors as they adopt a course management system. Educational Technology Research and Development 55(1): 1-26.

White, J. 2012. The impact of technology on student engagement and achievement in the mathematics classroom. Mastoral dissertation. Memorial University, New Zealand. 
Table 5: The learners' responses about learning Euclidean geometry with GeoGebra

\begin{tabular}{|c|c|c|c|c|}
\hline Questions & 1 & 2 & 3 & 4 \\
\hline 1. Were you excited about using GeoGebra? & $0 \%$ & $5 \%$ & $36 \%$ & $59 \%$ \\
\hline 2. Do you like studying circle geometry lessons with GeoGebra? & $4 \%$ & $9 \%$ & $25 \%$ & $62 \%$ \\
\hline 3. Did you feel confident using GeoGebra while learning? & $4 \%$ & $14 \%$ & $41 \%$ & $45 \%$ \\
\hline 4. Were you engaged in the learning process? & $0 \%$ & $4 \%$ & $21 \%$ & $75 \%$ \\
\hline 5. Did you benefit through GeoGebra, teacher-student interactions? & $5 \%$ & $4 \%$ & $41 \%$ & $50 \%$ \\
\hline 6. Were you able to use visualization skills during lessons? & $5 \%$ & $5 \%$ & $57 \%$ & $33 \%$ \\
\hline 7. Were you able to think creatively and critically in the discussion? & $5 \%$ & $1 \%$ & $45 \%$ & $48 \%$ \\
\hline 8. Did you make logical assumptions while hypothesizing? & $5 \%$ & $11 \%$ & $36 \%$ & $48 \%$ \\
\hline 9. Did you improve learning circle geometry using GeoGebra? & $2 \%$ & $16 \%$ & $5 \%$ & $57 \%$ \\
\hline $\begin{array}{l}\text { 10. Did you make connections between new and previous lessons while } \\
\text { using GeoGebra? }\end{array}$ & $7 \%$ & $13 \%$ & $18 \%$ & $62 \%$ \\
\hline 11. I will do well in Euclidean geometry tests and examination? & $9 \%$ & $13 \%$ & $5 \%$ & $73 \%$ \\
\hline $\begin{array}{l}\text { 12. Only brilliant learners can understand circle geometry without } \\
\text { GeoGebra? }\end{array}$ & $25 \%$ & $31 \%$ & $23 \%$ & $21 \%$ \\
\hline 13. Can Euclidean geometry improve your mathematics results? & $5 \%$ & $4 \%$ & $21 \%$ & $70 \%$ \\
\hline 14. Can circle geometry develop good reasoning skills? & $2 \%$ & $20 \%$ & $28 \%$ & $50 \%$ \\
\hline
\end{tabular}

\section{APPENDIX A: ACHIEVEMENT TEST (Post-test) \\ SCHOOL:}

Name:

Date:

Objectives: Stating theorems in words, calculations, and applications of theorems in complex problems.

Please mark the correct answer from those given

1. The line that is drawn from the center of the circle that bisects the chord is: Parallel to the chord; Perpendicular to the chord; Vertical to the chord; Double to the chord

2. Use the two following diagrams below to find the size of

2.1. $p$ is: $30 \mathrm{~mm} ; 80 \mathrm{~mm} ; 40 \mathrm{~mm} ; 50 \mathrm{~mm}$

2.2. $\mathrm{q}$ is equal to: $50 \mathrm{~mm} ; 40 \mathrm{~mm} ; 60 \mathrm{~mm} ; 30 \mathrm{~mm}$
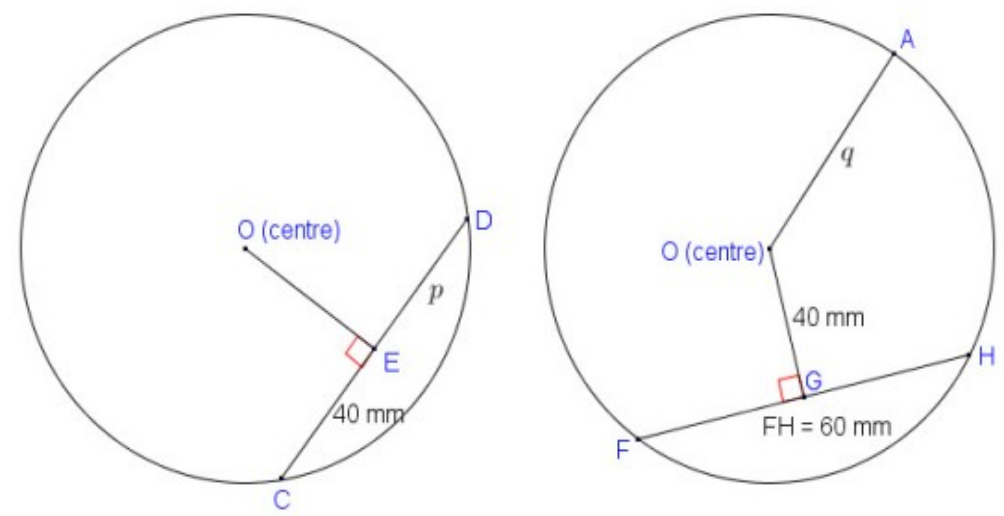

3. Use the following diagrams below to answer letter a to f:

3.1. The size of a is: $44^{0} ; 49^{\circ} ; 54^{0} ; 98^{0}$

3.2. The size of $b$ is: $48^{0} ; 24^{0} ; 96^{0} ; 44^{0}$

3.3. The size of $c$ is: $90^{\circ} ; 40^{\circ} ; 50^{\circ} ; 45^{0}$

3.4. The size of $d$ is: $136^{0} ; 58.5^{0} ; 234^{0} ; 117^{0}$ 
3.5. The size of e is: $90^{\circ} ; 100^{\circ} ; 80^{\circ} ; 180^{\circ}$

3.6. The size of $f$ is: $48^{\circ} ; 96^{\circ} ; 24^{0} ; 44^{0}$
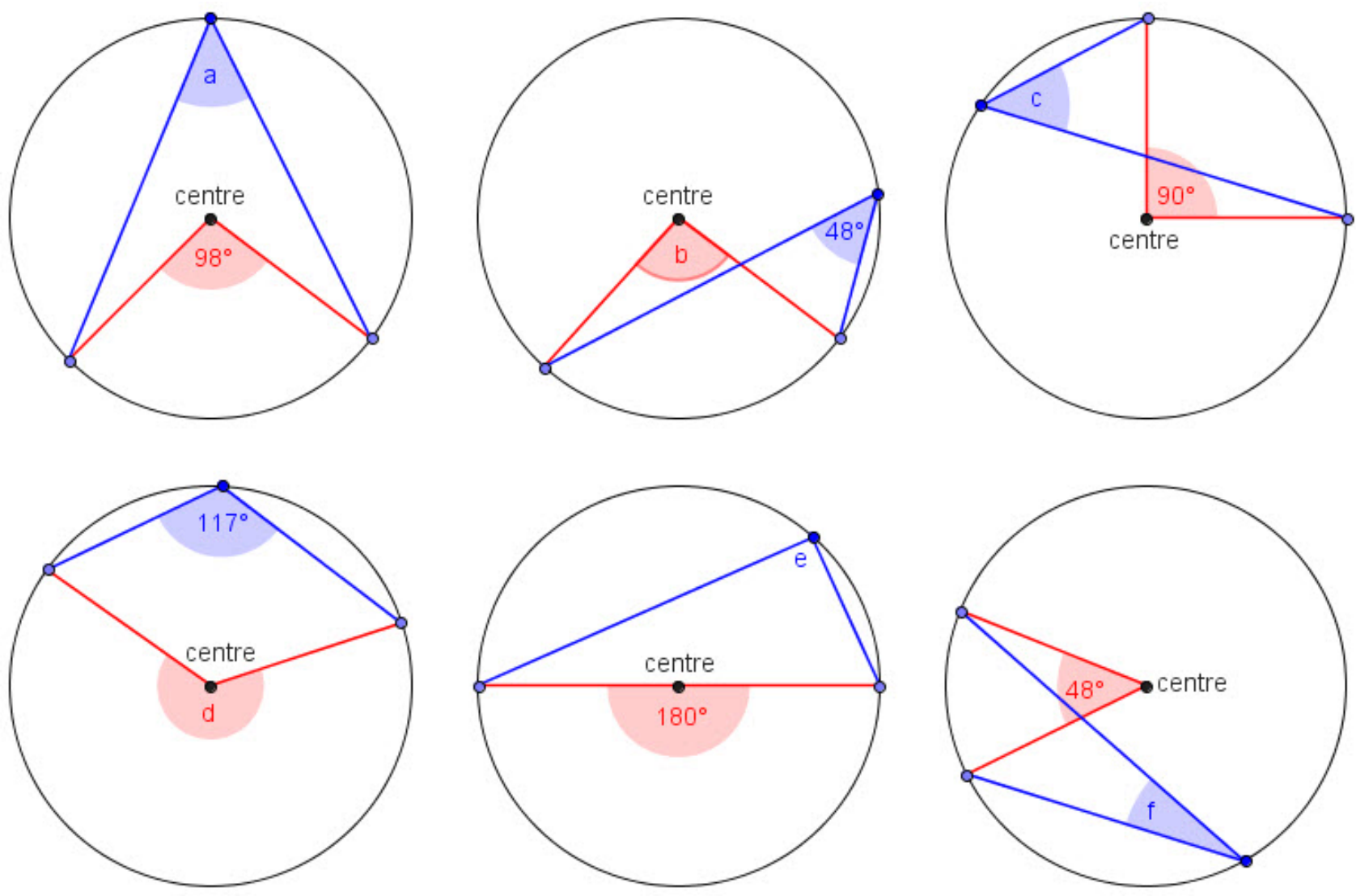

4. Use the following two figures to find the size of $a$ and $b$

4.1. The size of a is: $48^{0} ; 24^{0} ; 46^{0} ; 38^{0}$

4.2. The size of $b$ is: $71^{0} ; 51^{0} ; 102^{0} ; 61^{0}$

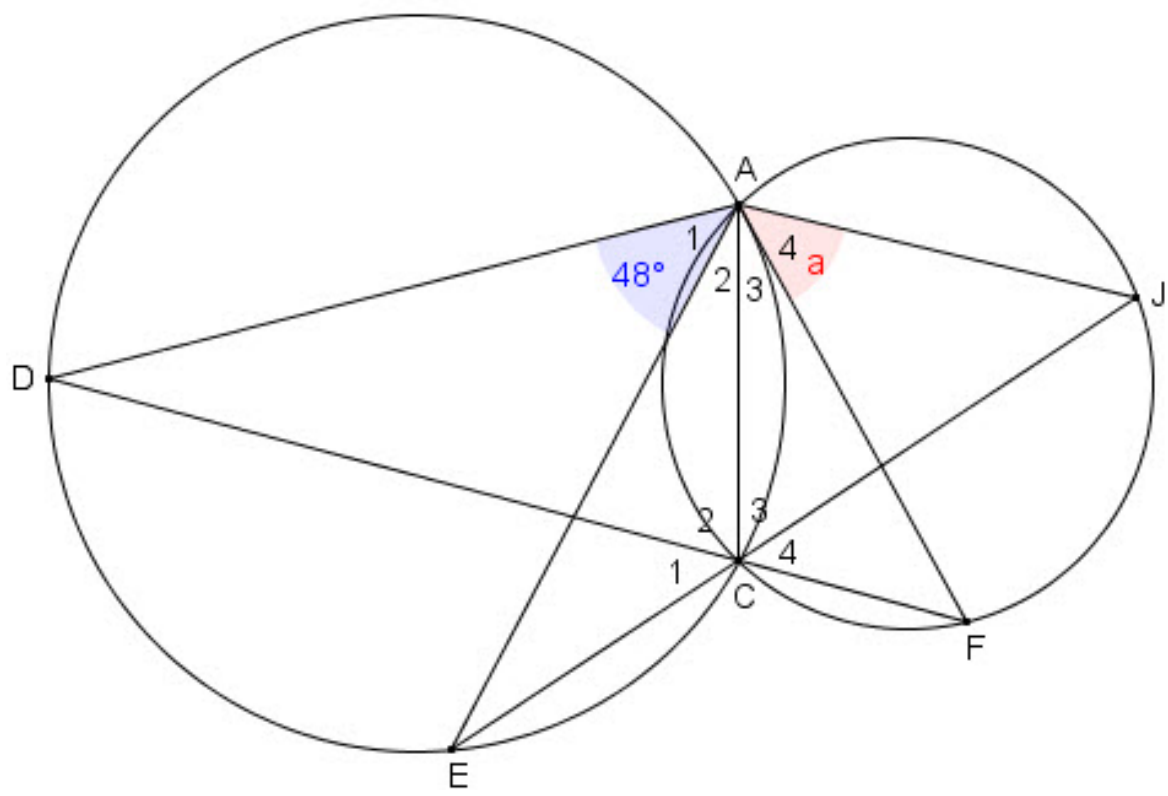




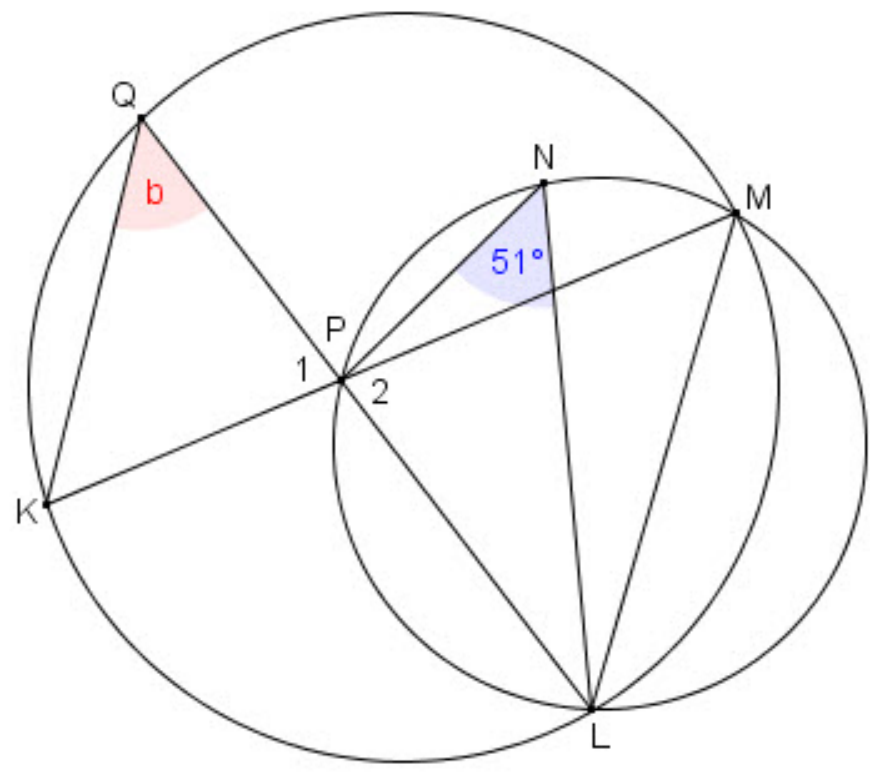

5. Complete the following statement. The opposite angles of a cyclic quadrilateral are: parallel; complementary; supplementary; perpendicular.

6. Refer to the following figures to find the size of $a, b, c$, and $d$

6.1. The size of a is: $94^{\circ} ; 84^{\circ} ; 96^{\circ}$

6.2. The size of $b$ is: $63^{0} ; 117^{0} ; 83^{0}$
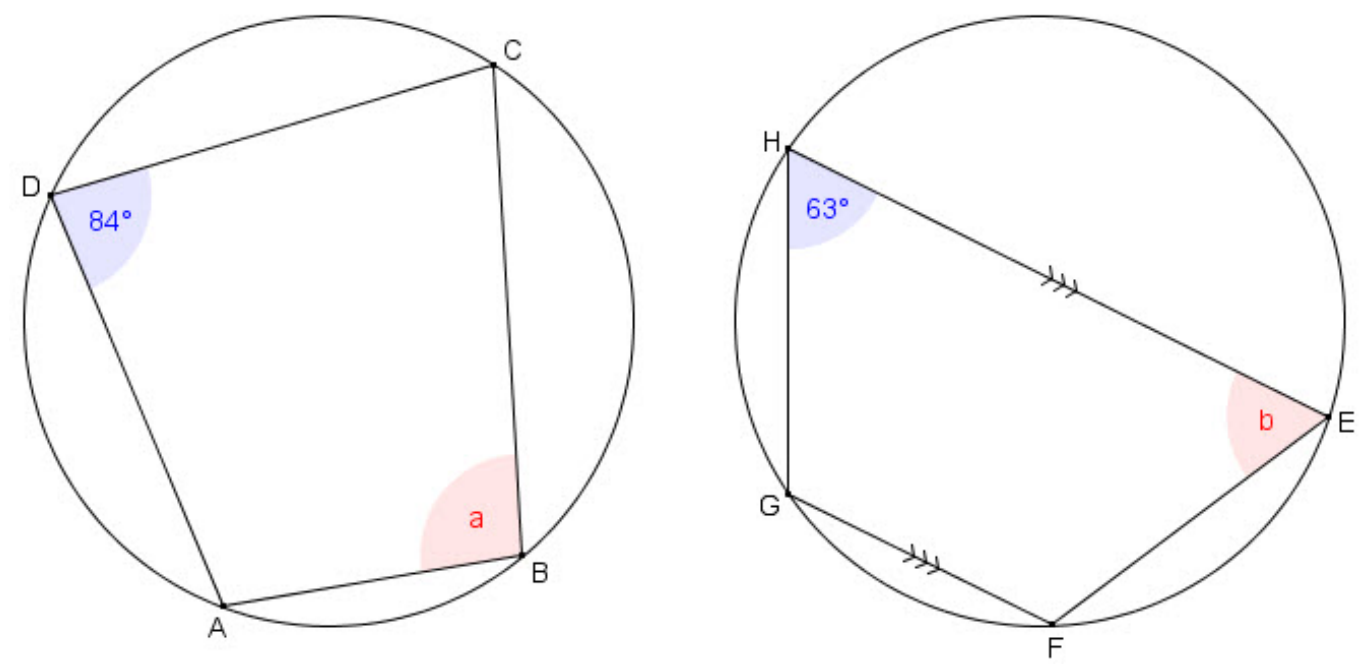